\title{
Preparation and Characterization of Hollow Spheres of Rutile
}

\author{
Stefanie Eiden ${ }^{1}$ and Georg Maret \\ Fachbereich Physik, Universität Konstanz, D-78457 Konstanz, Germany \\ E-mail: stefanie.eiden@uni-konstanz.de
}

\begin{abstract}
Hollow spherical particles of rutile were obtained by coating colloidal polystyrene beads with a titanium oxide hydrate layer and subsequently calcining at elevated temperatures under an oxygen atmosphere. In order to investigate the optimum conditions for the preparation of these hollow beads the maximum temperature and heating rate were systematically varied. The dimensions of the voids and the shell thickness of the hollow beads can be tailored by the size of the polystyrene beads and the thickness of the inorganic layer, respectively. 1002 Elsevier Science (USA)

Key Words: synthesis; hollow beads; $\mathrm{TiO}_{2}$; rutile.
\end{abstract}

\section{INTRODUCTION}

Mesoscale hollow spheres of ceramic materials have recently attracted much interest because these core-shell particles may exhibit properties that are substantially different from those of the core particles (1). It has been shown that the structure, size, and composition of these particles can be altered in a controllable way to tailor their optical, electrical, thermal, mechanical, electro-optical, magnetic, and catalytic properties over a broad range (2). Hollow particles represent a special case, since they can be used because of their lower density and particular optical properties as extremely small containers and as fillers or pigments (3). Furthermore, they are useful as building blocks for the formation of photonic crystals (4). Hollow spheres of rutile are very interesting because of their large contrast of refractive index, which is a prerequisite for materials with a complete photonic band gap (5).

Recently, two approaches for coating the polymer beads with a thin $\mathrm{TiO}_{2}$ shell have been reported. In the first method (6) the hollow $\mathrm{TiO}_{2}$ spheres were produced by coating crystalline arrays of monodisperse polystyrene beads in the solgel precursor solution. The second approach (7) relied on a double-template method. In this method a colloid crystal of silica beads is formed using a convective assembly process.

\footnotetext{
${ }^{1}$ To whom correspondence should be addressed. Fax: 0049-7531-883090.
}

These crystals were used as template to form a macroporous polymer. After removal of the silica beads the surface of the macroporous polymer was coated with $\mathrm{TiO}_{2}$. Both methods have been successfully applied for the formation of hollow $\mathrm{TiO}_{2}$ spheres. Nevertheless, the structure of the $\mathrm{TiO}_{2}$ of the materials was amorphous. Here we describe the sucessful synthesis of $\mathrm{TiO}_{2}$ hollow spheres consisting exclusively of crystalline rutile. Thereby, the refractive index is high enough to lead to a complete photonic band gap of the corresponding colloid crystals.

\section{EXPERIMENTAL}

\section{Materials}

Preparation of particles. Negatively charged sulfatestabilized polystyrene beads were prepared as described by Furusawa et al. (8). They were coated in a sol-gel process with $\mathrm{Ti}(\mathrm{OEt})_{4}$. Therefore, the polystyrene beads were dispersed in absolute ethanol by sonication. Subsequently, $\mathrm{Ti}(\mathrm{OEt})_{4}$ was rapidly added and the dispersion was stirred for $30 \mathrm{~min}$ in a closed PE bottle. Finally, the bottle was opened and the sol-gel precursor hydrolyzed into the oxide ceramic gel as a result of its exposure to the moisture of the ambient air. After a further $24 \mathrm{~h}$ of stirring under an ambient atmosphere part of the solvent was evaporated. A homogeneous dense thin coat around each polystyrene bead was formed. The beads were filtered and washed with distilled water. Polystyrene free $\mathrm{TiO}_{2}$ hollow spheres were obtained by a calcination in oxygen.

Analyses. The particle sizes of the dispersions were determined by transmission (Zeiss EM 900) and raster electron microscopy (REM) (Hitachi S-806C). The presence of the inorganic layer on the PS particles and their phases were determined by X-ray powder diffraction (Guinier Huber 670 ).

The weight loss of PS, $\mathrm{TiO}_{2} \cdot n \mathrm{H}_{2} \mathrm{O}$, and coated particles was determined using a Netzsch thermoanalyzer STA $429\left(\mathrm{O}_{2}\right.$ atmosphere, heating rate $5 \mathrm{~K} / \mathrm{min}$ ) combining thermogravimetry (TG), difference thermogravimetry (DTG), and difference thermal analysis (DTA). 


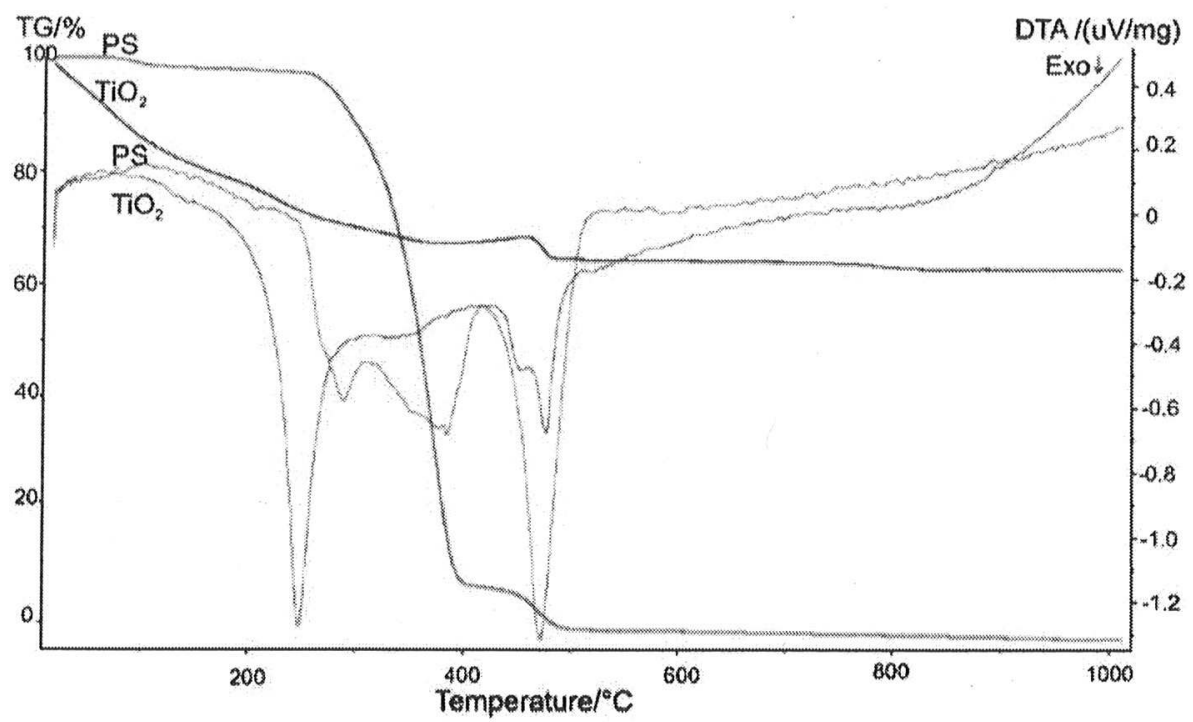

FIG. 1. Thermogravimetric analysis and differential thermal analysis curves of the polystyrene and coated beads.

\section{RESULTS}

\section{Preparation of Coated Particles}

The characteristics of the materials obtained from the different coating procedures are summarized in Table 1. To determine the optimum conditions for the coating of polystyrene with $\mathrm{TiO}_{2}$, several parameters were varied systematically, including the concentration of the reactant and reaction time. It is quite evident that the coating depended strongly on the concentration of $\mathrm{Ti}(\mathrm{OEt})_{4}$ in the reaction solution as well as on the reaction time. When the Ti(OEt $)_{4}$ was in excess, separate titania particles, besides the coated particles, were generated.

The thickness of the coating layer could be altered by the concentration of $\mathrm{Ti}(\mathrm{OEt})_{4}$ and the reaction time. When the solvent evaporated completely or the solvent was not stirred continually, aggregated particles were obtained.

TABLE 1

Properties of Spherical Coated Particles Obtained by Aging Ethanolic Dispersions Containing PS and Titanium Tetraethoxide

\begin{tabular}{|c|c|c|c|c|c|c|}
\hline Sample & $\begin{array}{c}\text { PS } \\
(\mathrm{g} / 10 \mathrm{ml})\end{array}$ & $\begin{array}{c}\mathrm{Ti}(\mathrm{OEt})_{4} \\
(\mathrm{ml} / 10 \mathrm{ml})\end{array}$ & $\begin{array}{l}\text { Coated } \\
\text { particle } \\
\text { diameter } \\
\quad(\mathrm{nm})\end{array}$ & $\begin{array}{c}\text { Thickness } \\
\text { of the } \\
\text { coat }\end{array}$ & $\begin{array}{c}\text { Reaction } \\
\text { time } \\
\text { (h) }\end{array}$ & $\begin{array}{l}\text { System } \\
\text { characte- } \\
\text { rization }\end{array}$ \\
\hline TLK $17 \mathrm{c}$ & 250 & 0.3 & 733 & 36.5 & 6 & $\mathrm{~S}$ \\
\hline TLK 17e & 250 & 0.3 & 830 & 85 & 24 & $\mathrm{R}$ \\
\hline TLK 17i & 250 & 0.3 & 900 & 120 & 31 & $\mathrm{R}$ \\
\hline TLK12 & 250 & 0.3 & 830 & 85 & 24 & $\mathrm{~S}$ \\
\hline TLK13 & 250 & 0.2 & 850 & 95 & 24 & $\mathrm{R}$ \\
\hline TLK 14 & 250 & 0.3 & 870 & 105 & 24 & $\mathrm{~S}$ \\
\hline TLK 15 & 250 & 0.4 & 900 & 120 & 24 & $\mathrm{~S}$ \\
\hline TLK16 & 238 & 0.5 & 900 & 120 & 24 & $\mathrm{~S}$ \\
\hline
\end{tabular}

Note. S, smooth coated beads; R, rough coated beads; $\mathrm{M}$, mixed systems consisting of coated particles and separated titania particles.

\section{Preparation of Hollow Particles}

Voids are obtained by the complete thermal decomposition in oxygen of polystyrene cores within the coated beads. Thermogravimetric analysis (Fig. 1) of the polystyrene and coated particles was carried out. The removal of water was observed between 50 and $250^{\circ} \mathrm{C}$, and the decomposition of the polystyrene between 300 and $450^{\circ} \mathrm{C}$. According to the TG results the calcination was performed at $600^{\circ} \mathrm{C}$ under an oxygen atmosphere. The REM (Fig. 2) of the products shows only hollow titania spheres. In some of them openings in the surface can be observed. The openings are probably due to the decomposition of the polystyrene beads. The voids are $25-30 \%$ smaller than the diameters of the original latex beads, indicating a shrinkage during the sintering process. A series of experiments has shown that the thickness of the $\mathrm{TiO}_{2}$ coating is an important factor for the stability of the hollow spheres. When the coat was too thin the hollow spheres partially burst. The optimum

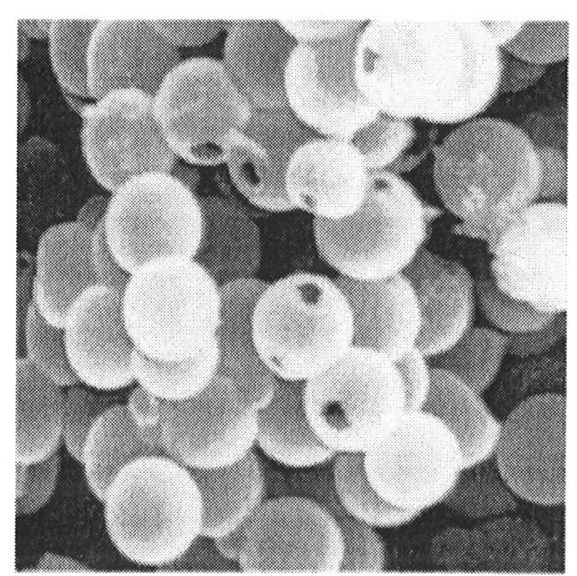

FIG. 2. REM of hollow beads obtained by calcining the coated particles at $600^{\circ} \mathrm{C}$ under an $\mathrm{O}_{2}$ atmosphere. 


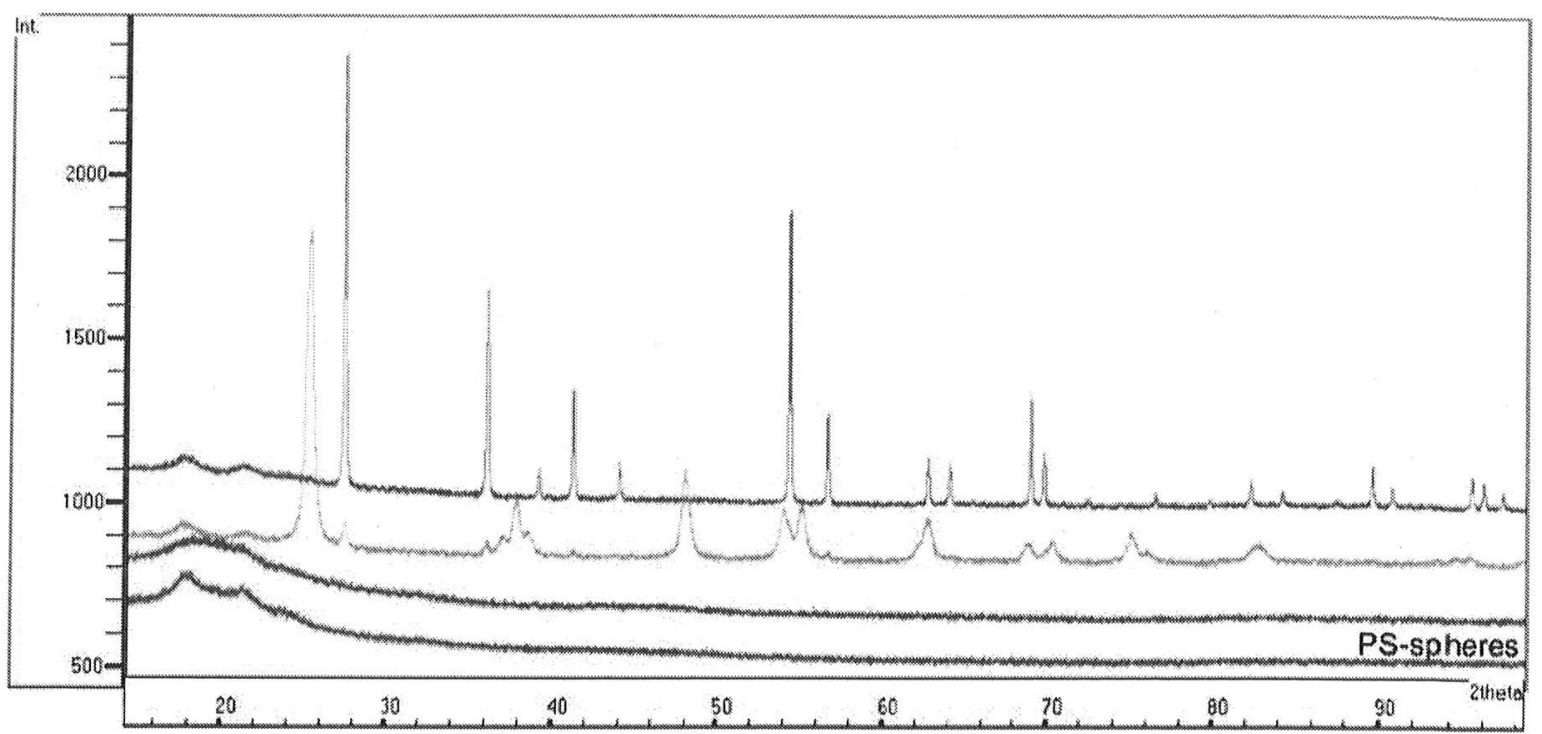

FIG. 3. X-ray diffraction patterns of polystyrene beads, the coated particles, and the same calcined at 600 and $1000^{\circ} \mathrm{C}$.

thickness of the coat was found to be in the range of 30 to $100 \mathrm{~nm}$.

The XRD patterns in Fig. 3 show the $\mathrm{TiO}_{2}$ phases formed at different temperatures. After the coating process the titania phase obtained is amorphous. When the coated particles were calcined at $600^{\circ} \mathrm{C}$ an anatase type of $\mathrm{TiO}_{2}$ with a small part of rutile was obtained. However, calcination at $1000^{\circ} \mathrm{C}$ yielded

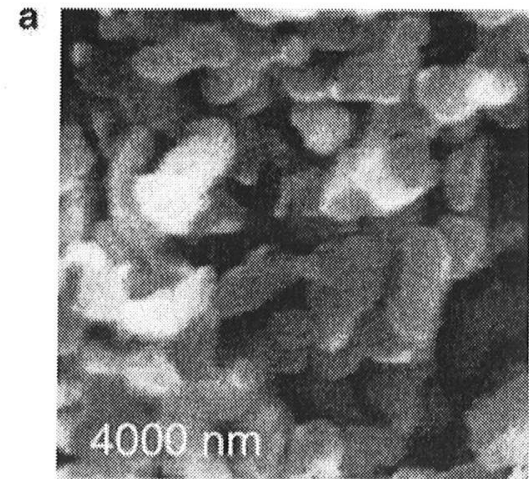

b.

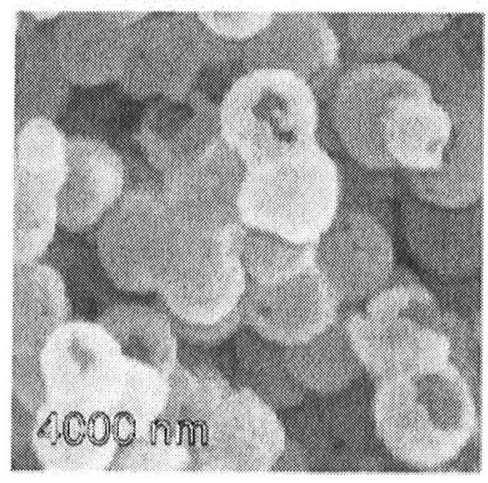

FIG. 4. REMs of particles obtained at $1000^{\circ} \mathrm{C}$ whose polystyrene core was (a) smaller then $850 \mathrm{~nm}$ and (b) larger than $850 \mathrm{~nm}$.
$\mathrm{TiO}_{2}$ particles consisting exclusively of rutile. The REMs of Figs. $4 \mathrm{a}$ and $4 \mathrm{~b}$ show nanoparticles and in some cases hollow rutile spheres, respectively. The relations between the reaction conditions and the products are shown in Table 2. When the diameter of the polystyrene beads was larger than $850 \mathrm{~nm}$, hollow rutile spheres were obtained. Otherwise, nanoparticles were created. Possibly, when the diameter of the polystyrene beads is smaller the curvature of the coat is probably too high for the formation of a stable rutile phase, so that a strain is built up and the hollow spheres breaks into nanoparticles. The structure of rutile, consisting of edge-linked blocks, is probably less flexible than the structure of anatase, consisting of edge- and corner-linked units. These results are in good agreement with those of Shiho and Kawahashi (9). They described that their hollow anatase spheres having a diameter of $480 \mathrm{~nm}$ burst into nanoparticles at $900^{\circ} \mathrm{C}$, too.

TABLE 2

The Influence of the Size of the Polystyrene Beads on the Hollow Beads

\begin{tabular}{lcccc}
\hline Sample & $\begin{array}{c}\text { Diameter of } \\
\text { the polystyrene } \\
\text { spheres (nm) }\end{array}$ & $\begin{array}{c}\text { Thickness of } \\
\text { the } \mathrm{TiO}_{2} \\
\text { coat }(\mathrm{nm})\end{array}$ & $\begin{array}{c}\text { Anatase } \\
\text { hollow } \\
\text { sphere }\end{array}$ & $\begin{array}{c}\text { Rutile } \\
\text { hollow } \\
\text { sphere }\end{array}$ \\
\hline TL1 & 1300 & 40 & ++ & + \\
TL2 & 1100 & 30 & ++ & + \\
TL11 & 888 & 25 & + & - \\
TL12 & 888 & 45 & ++ & + \\
TL13 & 888 & 20 & + & - \\
TL19 & 800 & 100 & + & - \\
TL20 & 555 & 40 & + & - \\
TL21 & 611 & 10 & ++ & - \\
TLK1 & 527 & 50 & & - \\
\hline
\end{tabular}

Note ++ , perfect hollow spheres; + , hollow spheres with many openings in the surface; - , no hollow spheres. 


\section{CONCLUSION}

We present a novel and simple synthesis of rutile hollow beads. The voids of these hollow spheres were determined by the diameter of the polystyrene template, and the thickness of the ceramic wall could easily be tailored in the range of 10-100 nm by using precursor solutions with different concentrations.

Depending on the maximum calcination temperature the $\mathrm{TiO}_{2}$ shell of the hollow beads was either anatase or rutile. Polystyrene beads larger than $850 \mathrm{~nm}$ in diameter yielded the desired hollow rutile beads.

\section{ACKNOWLEDGMENTS}

We kindly acknowledge access to characterization techniques in the groups of Professors Felsche, Leiderer, and Rathmayer, as well as financial support by the Deutsche Forschungsgemeinschaft in the frame of the Schwerpunkt SPP 1113.

\section{REFERENCES}

1. Caruso, F., Chem. Eur. J. 6, 413 (2000).

2. Aden, A. L., and Kerker, M., J. Appl. Phys. 22, 1242 (1951); Oldenburg, S. J., Averitt, R. D., Westcott, S. L., and Halas, N. J., Chem. Phys. Lett. 288, 243 (1998).

3. Ohmori, M., and Matijevic, E., J. Colloid Interface Sci. 150, 594 (1992).

4. Busch, K., and John, S., Phys. Rev. B 58, 3896 (1998).

5. Joannopoulos, J. D., Villeneuve, P. R., and Fan, S., Nature 386, 143 (1997).

6. Zhong, Z., Yin, Y., Gates, B., and Xia, Y., Adv. Mater. 12, 206 (2000).

7. Rengarajan, R., Jiang, P., Colvin, V., and Mittleman, D., Appl. Phys. Lett. 77, 3517 (2000)

8. Furusawa, K., Norde, W., and Lyklema, J., J. Kolloid Z. Z. Polym. 250, 908 (1972).

9. Shiho, H., and Kawahashi, N., Colloid Polym. Sci. 278, 270 (2000). 